\title{
Research on Building Industry in U.S. Stock Market during COVID-19
}

\author{
Yiwa Lai ${ }^{1, \dagger}$ Feiming Qiu ${ }^{2, \dagger}$ Wenkai Xu ${ }^{3, \dagger}$ Yujing Yang ${ }^{4, *,}$ \\ ${ }^{1}$ University of Science and Technology Beijing, Beijing, 100000, China \\ ${ }^{2}$ East China University of Science and Technology, Shanghai, 200000, China \\ ${ }^{3}$ Beijing University of Technology, Beijing, 100000, China \\ ${ }^{4}$ Shanghai Lixin University of Accounting and Finance, Shanghai, 200000, China \\ * Corresponding author: e-mail: guanghua.ren@gecacademy.cn \\ These authors contributed equally.
}

\begin{abstract}
The pandemic caused by Covid-19 has created a severe global economic recession and destroyed many industries since it broke out at the beginning of 2020. However, many companies in construction material industry had an outstanding performance last fiscal year. This paper applied Fama-French five-factor model to analyze the effect on the construction material industry under the Covid-19. Based on the daily five-factor data (US construction material industry stocks) from the US database, this paper selects the corresponding 18-month data, with the outbreak point of March 2020 as the dividing line (March 2020 to November 2020 is post-epidemic, while June 2019 to February 2020 is pre-epidemic). During the process of multiple-regression analysis, each coefficient of different factors has been compared, and then, it has been found that HML and RMW both have significant changes. COVID-19 has a dramatic positive effect on the construction material industry and investors prefer to invest in the companies with small scale and robust profitability.
\end{abstract}

Keywords: Fama-French model, COVID-19, Construction material industry, U.S stock market

\section{INTRODUCTION}

In February 2020, Covid-19 spread in the whole world, including the United States with around 0.6 million Americans dying in the new pandemic by April 2021. At the same time, the epidemic has affected economies around the world, especially tumbling the US stock market. By the end of the day on March 12th, all three major US stock indexes had fallen to nearly $10 \%$, worse than the worst one-day drop during the 2008 financial crisis. In March 2020, the US stock market crashed twice, and the Federal Reserve took emergency measures to rescue the market. Remarkably, after the FEDs rare emergency cut of 50 basis points, the target range of the benchmark federal funds rate dropped down to between $1.0 \%$ and $1.25 \%$, which has never fallen below the range of $0 \%$ to $0.25 \%$. Implausibly, after nearly half a year of regulation, the US stock market has repeatedly created a record high. At the end of the fiscal year 2020, the S\&P 500 index SPX, $-0.48 \%$, notched its record closing high, ending up $0.6 \%$ to 3,756 . The Nasdaq Composite Index closed just shy of a record, up

\section{$0.1 \%$ at 12,888 .}

Capital Asset Pricing Model (CAPM) is the first equilibrium model of financial asset pricing as well as the first financial asset pricing model that can be tested [1]. The primary significance of this model is to establish the relationship between capital risk and return, clearly indicating that the expected rate of return of securities is the sum of risk-free rate of return and risk compensation, and revealing the internal structure of securities return. Generally, CAPM, one of the most important topics in financial economics, tries to explain the price or value of assets that will be paid in the future under uncertain conditions. In this theory, "assets" usually refers to financial instruments or certain securities, and "price" is the price of their market equilibrium (the price determined by market demand and supply). It has been found that low asset prices imply high returns, then this theory is considered to explain why some assets pay more on average than others. Afterwards, this topic has been developed for many times, solving the anomaly problem. Fama and French proposed the three and five factor model $[2,3]$, 
which has been widely applied in many fields [2,3].

After the outbreak, many research focused on the economic effect of the COVID-19. Callin in his study looked at how a global pandemic (COVID-19) can influence the market, which causes disrupt the generation or flow of available information and thus a significant derivation of prices from their equilibrium values. His analysis also proved his hypothesis that these inefficiencies may have a greater effect on some industries than others, observing that the global COVID-19 pandemic leads to statistically significant increases in the volatility of industries such as Meals, Games, and Mines relative to the market as well as a significant liquidity deterioration relative to the market in industries including ElcEq, Carry, and Other [4]. Khatatbeh et al. investigated the immediate reaction of affected countries stock market related to COVID-19. They applied the standard event study methodology of Brown and Warner (1985) to test how stock markets react to the COVID-19 pandemic outbreak and measured the deviation of the stock market index from their historical average. They found that global stock markets have correctly anticipated the COVID-19 disastrous impact, as shown by the significant negative ARs and CARs, particularly following the WHO announcement [5]. Using the Daily News Sentiment Index (DNSI) and Google Trends data, Lee find what effect has COVID-19 brought to the US stock market from January 21st, 2020 to May 20th, 2020 according to the data from Daily News Sentiment Index (DNSI) and Google Trends. What is more, based on the regression model of optimal return the exam tries to distinguish whether DNSI may change US industry returns. In the end, the author also gives some plans of investment strategies according to the correlation level of time lag perspectives by visualizing changes [6]. Pavlyshenko investigates different regression approaches for modeling COVID-19 spread and its impact on the stock market. He used logistic curve model with Bayesian regression for predictive analytics of the coronavirus spread and studied impact of COVID-19 by using regression approach and comparing to other crises influence. The obtained results show that different crises with different reasons have different impact on the same stocks. It is important to analyze their impact separately. The uncertainty of coronavirus crisis is larger comparing to other crises that can be caused by shorter analysis time [7]. Contessi et al. investigates that association between the instability and a sudden collapse of stock markets. They documented the extent of instability and distress across stock markets, and identified periods of instability in these markets. By testing for transmission of instability from market to market, they found that instability is associated with a sudden collapse of stock markets, while the recovery is smoother. They provided evidence of statistical transmission of instability from China to all other economies during the first three months of 2020 [8]. The investigation studies by Huang illustrate what impact has COVID-19 brought to the stock performance of brand equity. The article surge that only top brands that owe consumers' loyalty may retain stable cash flows and mitigate the macroeconomic. Most of them had higher stock returns but lower systematic risk and idiosyncratic risk in the Covid-19 crash than other firms. What is more, the study can also be used to classify the impact of corporate social responsibility on stock performance between different brands [9]. The study, wrote by Adam et al. invested the what did 67 equity markets do all over the world during the COVID-19 outbreak in 2020, including the factors from finance, economics, demographics, technological development, healthcare, governance, culture, and law. And even government interventions, for instance, containment and closure policies, and economic stimuli. The findings demonstrate that stock markets in countries with low unemployment rates and populated with firms with conservative investment policies. In the end, the team gives a result that the expecting returns have less possibility to be impacted by the healthcare crisis [10].

Many researchers have applied Fama-French model in different stock market. Abderrazak and Nesrine investigated in their paper the effect of the asset valuation predictive power of investor sentiment on the US stock market. Two additional variables: the momentum factor and an investor sentiment index are added to conduct a revised Fama-French model. Dividing the full samples by size and value, size and profitability, and size and investment, the authors find that the investor sentiment has a mixed effect on asset valuation by examining SMB, HML, RMW and CMA. In general, the investor sentiment-asset value relationship is highly sensitive to the vatiability in capital invested, profitability and portfolio size [11]. Mosoeu and Kodongo tried in their paper to illustrate the priced equity risk factors in emerging markets to help portfolio investors make investment choices for the understanding of the priced equity risk factors in these markets is unclear. The authors find that RMW explains best of the return on equity of the emerging markets when using GMM. In conclude, the five-factor model performs well in Australia, China and South Africa as the data shown are consistent with those of the research, but it shows trivial or even negative relationship with America and Japan for it presents opposite data [12]. Li et al. make use of the Fama-French Three-Factor Model in their paper for the analysis of stocks of Chinese blockchain firms and to detect the existence of size effect and book-to-market ratio effect in this field. At the same time, they added the sentiment factor into the model, utilizing investors' mood for mining and quantifying to construct a sentiment index, since sentiment could be a new independent variable to enhance the explanatory power of the model, raising the explanatory power. They found that the Chinese 
blockchain industry does not own the size effect and book-to-market effect [13].

In addition, some scholars tried to use this model to explore the problem of COVID-19. Horvath and Wang investigated in their paper whether Fama-French 5-factor model can explain the monthly excess returns in selected events, measured by parameter $\mathrm{R}^{2}$, including financial crisis and COVID-19 epidemic situation. They find that the five-factor models maintain the $\mathrm{R}^{2}$ value on a high enough level and only one researched $R^{2}$ of COVID-19 time rises to the highest during the whole observation period. In conclude, the $\mathrm{R}^{2}$ of growth portfolios plummets during the financial crisis of 2008 . The Covid-19 outbreak, though on-going, has led to a plunge in the $\mathrm{R}^{2}$ during the period [14]. Liu and Jolla investigated in their paper the difference of performance of the service industry in the USA before and after the influence of COVID-19 and their prediction of the industry, through using the Fama-French model to figure out and analyze the 5 factors with the data from American Database. They generally find that all five factors market, size, value, profitability, and investment changed in different degrees, which means that the performance of service industry is related to those 5 factors [15].

As mentioned above, the Fama-French model is a relatively reliable asset pricing model and can be used in many areas. This research aims to explore the initial impact of COVID-19 on the US stock market by using Fama-French model. Although the outbreak of COVID-19 is impacting almost all industries and sectors worldwide, it is discovered that construction material industry was influenced greatly according to the statistics of the US stock market from Kenneth R. French's database. By comparing different factors, this study committed to find that which factor shows a huge effect on the market from various perspectives. The research also studied the impact of the epidemic on the industry by comparing the relevant indexes of the industry before and after the epidemic. The investigation will also give relative investment recommendations on the construction material industry in the US stock market. Under present circumstance, the article can offer a comprehensive view of the impact of COVID-19 on the US stock market and especially the changes of construction material industry under the epidemic situation and provide reference for future investment decision.

\section{METHOD}

Fama and French analyzed the factors which could determine the discrepancy of the return on various stocks in the American stock market. They found that the beta value of the stock market was not able to explain that discrepancy, which, instead, could be interpreted by market risk, market value risk and book-to-market risk. Consequently, Fama and French maintained that the excess returns above were the compensation for the risk factors that were failed to be reflected by CAPM and Fama-French three-factor model was then put forward as displayed below [2]:

$$
\mathrm{Ri}=\mathrm{Rf}+\beta \mathrm{mkt}(\mathrm{Rm}-\mathrm{Rf})+\beta \mathrm{smbSMB}+\beta \mathrm{hmlHML}+
$$
घi (1)

where $\mathrm{Ri}$ refers to the rate of return on portfolio $\mathrm{i}$; $\mathrm{Rf}$ refers to the risk-free rate; Rm refers to market return; (Rm-Rf) refers to market risk premium; SMB (Small Minus Big) is the simulated portfolio return rate based on size factor; HML (High Minus Low) is book-to-value factor, representing the excess financial dilemma risk with a higher appraisement in the market than in the inner corporation; $\beta \mathrm{mkt}, \beta \mathrm{smb}$ and $\beta \mathrm{hml}$ are the coefficients of the three factors, respectively.

After that, some modifications were made to the original model by Fama and French for they found that earnings level risk and investment level risk could also lead to excess earnings of individual share [3]; therefore, Fama-French five-factor model was then proposed as shown below:

$\mathrm{Ri}=\mathrm{Rf}+\beta \mathrm{mkt}(\mathrm{Rm}-\mathrm{Rf})+\beta \mathrm{smbSMB}+\beta \mathrm{hmlHML}+\beta \mathrm{rm}$ $\mathrm{wRMW}+\beta \mathrm{cmaCMA}+\varepsilon \mathrm{i}$

The added factor RMW (Robust Minus Weak) refers to the profitability factor, demonstrating the potential higher risk among the high-profit industry; CMA (Conservative minus Aggressive) presents the investment level risk, measured by the reinvestment rate and the lower the reinvestment rate, the higher the risk.

\section{RESULTS}

In order to evaluate the influence of COVID-19, the statistics of the US stock market from Kenneth R. French's database was adopted. The period was selected from June 2019 to February 2020 and March 2020 to November 2020 which reflected two different situations between normal days and the COVID-19 outbreak, respectively. By using the regression model to obtain the coefficients, and the two tables has been shown as follows.

TABLE 1 Regression results before Covid-19 (2019.06-2020.02)

\begin{tabular}{lllll}
\hline & Coefficients & $\begin{array}{l}\text { Standard } \\
\text { Error }\end{array}$ & t Stat & P-value \\
\hline Intercept & 0.08 & 0.07 & 1.21 & 0.23 \\
MKT-RF & 0.87 & 0.08 & 10.80 & 0.00 \\
SMB & 0.63 & 0.15 & 4.15 & 0.00 \\
HML & 0.34 & 0.15 & 2.18 & 0.03 \\
RMW & -0.08 & 0.25 & -0.29 & 0.77 \\
CMA & -0.14 & 0.29 & -0.48 & 0.63 \\
\hline
\end{tabular}


TABLE 2 Regression results after Covid-19 (2020.03-2020.11)

\begin{tabular}{l|llll}
\hline & Coefficients & $\begin{array}{l}\text { Standard } \\
\text { Error }\end{array}$ & t Stat & P-value \\
\hline Intercept & 0.03 & 0.07 & 0.47 & 0.64 \\
MKT-RF & 1.04 & 0.03 & 34.09 & 0.00 \\
SMB & 1.03 & 0.08 & 12.75 & 0.00 \\
HML & 0.07 & 0.07 & 1.12 & 0.26 \\
RMW & 0.30 & 0.14 & 2.11 & 0.04 \\
CMA & 0.15 & 0.18 & 0.85 & 0.39 \\
\hline
\end{tabular}

As shown in tables, the coefficient of MKT was above 1 after the outbreak, and SMB was significant in both period. Particularly, HML tended to be insignificant during Covid-19, and RMW had the opposite performance. CMA was always redundant.

\section{DISCUSSION}

\subsection{Mkt}

Mkt of the construction material industry increases from 0.87 to 1.04 , which represents that the sensitivity of construction material industry's stock price to market rose. The increase of the data also shows a more sensitive sector relative to the market. The main reason why the market appeared more sensitive will be illustrated as follows.

The price of wood, used as a raw material for construction, had risen repeatedly during the epidemic. As of February 18, 2020, according to Random Tense, the price reached $\$ 992$ per thousand board feet of wood. Lumber prices had risen 180 percent since the outbreak. At this lumber prices, the cost of raw materials for a typical new single-family home would rise by $\$ 24,000$, according to calculations by the National Association of Home Builders. In the spring of 2020, after states issued lock downs, sawmills across the country shut down, reducing supplies. At the same time, Americans living in isolation at home realized that this was a great opportunity to do home renovations or craft projects. As a result, demand for wood soared. Also, a surge in confirmed cases of COVID-19 in the United States in the final weeks of 2020 had slowed production at sawmills, especially in the sought-after California redwood region. This had again caused lumber prices to soar.

On the other hand, during COVID-19, the demand for plastics remained high. Building materials, as downstream industries, were in short supply. A U.S. manufacturer of housing construction materials said it was already struggling to get resins, paints and adhesives during the new outbreak, lead times were longer and costs were rising sharply as raw material prices rise.

Similar to the above raw materials, many other raw materials were also in this situation during the COVID-19 time. As demand increased and supply decreases, the supply fell short of the demand, which made the price of raw materials rise, which also became the main reason for the market to be more sensitive after the epidemic.

\section{$4.2 S M B$}

With regard to SMB which illustrates the choice of investing between small-cap company and the large one. According to the statistics that has been shown in the tables, the SMB is significant both before and after the pandemic with 4.15 and 12.75, respectively. Meanwhile, the $\beta$ coefficient of SMB increase from 0.63 to 1.03 which indicates that investors preferences to small-cap company rises. The possibles reasons in two different time bucket will be illustrated as follows.

Before the outbreak of COVID-19, small-cap firms might be risky than the larger ones, therefore there will be a higher risk premium as compensation.. According to Rebecca in Russell 2000 index, small-cap stocks performed better than large-cap stocks in the S\&P 500 20 times in a period of 36 years from 1979 to 2015 [16]. What is more, small-cap company may have potential to growth. As Troy said younger firms might bring new product or services that can creating new market [17]. Meantime, small-cap companies play an important role when diversify the risk of investment. So, if the investors aims at making profit through investing, choose a small-cap firm might be more promising than large firms.

When the pandemic came, although the whole stock market was damage badly, small-cap firm is also a good choice compared to large one. Most of the small company are likely to spring back the most after the journey. These stocks are likely to do well after the recession which did better as well in the nine of the last 10 recessions [18]. Apart from that, Some specific small-cap company is also promising. For instance, small-cap coronavirus stock has a jump of over $400 \%$ [19]. Therefore, instead of investing large company, making profit form small medical company also took a large proportion among all the investors.

\section{$4.3 \mathrm{HML}$}

When it comes to the HML factor, it expresses that corporations with high book-to-market ratios (value stocks) outperform those with low ones (growth stocks). Besides, it can also be concluded that if a company purchases more value stocks, the model regression would show a positive relation to the HML factor.

As mentioned in the result, the t-statistics becomes insignificant when compared to that before the epidemic period, which indicates that prior to the COVID-19, the company prefers value stocks rather than growth stocks 
in that as a conventional industry, the value stocks of construction material tended to be stable, favored by the investors. However, this kind of preference cannot be differentiated when suffered from the epidemic period. The reason is that the epidemic shock has formed a conducive impact on the whole construction material industry, leading to a promising prospect with some incentive policies, and a refreshed environment throughout the industry.

Due to a combined effect of the increase in lumber price, advantageous post-epidemic policy and the willing to move suburb to escape from the COVID-19, the stock of construction materials has once rejuvenated since April, 2020. The stock prices of the leading construction companies such as Holden House (DHI.N) and Lenner House (LEN.N) have increased by more than $90 \%$ between the months between April and August in 2020. The estimated expenditure on new construction throughout the United States will even reach USD 1.45 trillion in 2023, tending to a better prospect.

\subsection{RMW}

As shown in Table 1 and Table 2, the t-value of RMW before the epidemic presents insignificance, which means that its coefficient value was not significantly different from 0 . Meanwhile, after the outbreak, the t-value of RMW turned to be significant with a positive coefficient.

This change indicates that investors were not optimistic about the overall development of the construction material industry after the outbreak of COVID-19, and they tended to focus on centain profit because robust companies usually have steady financial situations, although they used to pay little attention to this point before. Generally, the revenue of these companies can grow steadily, although sometimes modestly. At the same time, their net profits can keep pace with the growth, and their cash inflows can be kept greater than its outflows most of the time, which means less risk for investors as well. As a result, when the stock market is depressed, those mature companies can be a good choice for investment.

For instance, Summit Materials Inc., a Top10 construction materials provider of products such as gravel, construction gravel, cement and ready-mixed concrete, as well as paving and construction services, is a robust mature company whose stock did not fare well before the outbreak. However, after March 2020, its closing price nearly doubled from $\$ 15$ to $\$ 28$. Admittedly, such growth has also been driven by preferential policies. But there is no doubt that most investors prefer robust mature companies for perpetually steady profits.

\section{$4.5 C M A$}

As for the CMA factor, however, when compared the coefficients before and after the epidemic break, there was really not much difference in the preference of conservative or aggressive stock of construction material industry.

The reason for this insignificant situation was that the epidemic continues to worsen, the rise and fall of the U.S. stock were mixed and uncertain. Consequently, the risk appetite of the investors only focused on several specific stocks and placed more emphasis on long-term growth stocks such as technology stocks. Nevertheless, investors truly cared less about whether invested into conservative stocks or aggressive ones in construction material field.

\section{CONCLUSION}

Focusing on US stock market, the article investigate the what influence COVID-19 has brought to building materials according to Fama-French five-factor model. To sum up, the result of this study is more investors turn out to be more favor on investing small-cap company, however the result of statistics indicate that there are little difference between large-cap firm and the small one. Although the all the stock market has been severely damaged in the first several months after the outbreak began and look down on the trend of stock, surprisingly, the market of building trades came back to vitality from March, 2020 and the trend kept surging for the next year. As far as concerned, the stock market might keep its trend in 2021 as well, therefore this paper highly recommends to take these stocks also into account and both large firm and the small one is both worth to invest.

\section{REFERENCES}

[1] William F Sharpe, (1964), "Capital Asset Prices: A Theory of Market Equilibrium under Conditions of Risk", The Journal of Finance, vol.XIX, No.3

[2] Fama, E. F., \& French, K. R. . (1993). Fama-French APT three-factor model.

[3] Eugene F. Fama and Kenneth R. French, (2013), A Five-Factor Asset Pricing Model, Unpublished intranet document.

[4] Callin Christensen. (2020). The Relativ The Relative Industr e Industry Specific E y Specific Effects of CO ects of COVID-19 on Mark VID-19 on Market Volatility and Liquidity.

[5] Ibrahim N. Khatatbeh1, Mohammad Bani Hani1, Mohammed N. Abu-Alfoul2. (2020). The Impact of COVID-19 Pandemic on Global Stock Markets: An Event Study, Unpublished intranet document. 
[6] Lee, H.S. (2020), Exploring the Initial Impact of COVID-19 Sentiment on US Stock Market Using Big Data", Sustainability (Basel, Switzerland), vol. 12 , no. 16 , pp. 6648.

[7] Pavlyshenko, B. M. (2020). Regression approach for modeling covid-19 spread and its impact on stock market.

[8] Contessi, S. , \& Pace, P. D. . (2020). The international spread of covid-19 stock market collapses. Economics Department, Working Paper Series.

[9] Huang, Y., Yang, S. \& Zhu, Q. (2021). "Brand equity and the Covid-19 stock market crash: Evidence from U.S. listed firms", Finance research letters, pp. 101941.

[10] Zaremba, A., Kizys, R., Tzouvanas, P., Aharon, D.Y. \& Demir, E. (2021), "The quest for multidimensional financial immunity to the COVID-19 pandemic: Evidence from international stock markets", Journal of international financial markets, institutions \& money, vol. 71, pp. 101284.

[11] Dhaoui, A. \& Bensalah, N. (2018). Asset valuation impact of investor sentiment: a revised famafrench five-factor model. Journal of Asset Management, 18(1), 1-13.

[12] Mosoeu, S., \& Kodongo, O. (2020). The fama-french five-factor model and emerging market equity returns. The Quarterly Review of Economics and Finance.

[13] Ziyang Ji, Victor Chang, Hao Lan, Ching-Hsien Robert Hsu and Raul Valverde. (2020). Empirical Research on the Fama-French Three-Factor Model and a Sentiment-Related Four-Factor Model in the Chinese Blockchain Industry.

[14] Dominik Horváth and Yung-LinWang. (2020). The examination of Fama-French Model during the Covid-19, Unpublished intranet document.

[15] Shijing Liu and La Jolla. (2020). Analysis of COVID-19 on Service Industry Based on Fama and French Five-Factor Model, Unpublished intranet document.

[16] Rebecca, L “Top 3 Reasons to Invest in Small-Cap Stocks" 2019, AUG 15 https://smartasset.com/investing/top-3-reasons-to-i nvest-in-small-cap-stocks

[17] TROY, S “Small Cap Investing: An Introduction" 2020 , Feb 23 https://www.investopedia.com/investing/introducti on-to-small-cap-stocks/\#: :text=The $\% 20$ primary $\%$ 20advantage $\% 20$ of $\% 20$ investing $\% 20$ in $\% 20$ individ ual $\% 20$ small-cap,acquisition $\% 20$ activity $\% 20$ provi des $\% 20$ another $\% 20$ opportunity $\% 20$ for $\% 20$ small-c ap\%20investors.

[18] Larry, L "Why To Buy Small-Cap Stocks Now" 2020, May 31.https://www.forbes.com/sites/lawrencelight/202 0/05/31/why-to-buy-small-cap-stocks-now/?sh=4f7 $5 \mathrm{f} 2501495$

[19] Bryan, M "Small-cap Coronavirus Stocks Perform in Face of COVID-19" 2020, September 7th.https://investingnews.com/daily/life-science-in vesting/biotech-investing/small-cap-coronavirus-st ocks. 